unhappy in the home, as she would rather be with Cynthia and would also be upset if Cynthia was distressed by her mother being placed in residential care. It is therefore questionable whether this would be a 'good' outcome. Perhaps with the dependent sick, professionals need to pay as much attention to the needs of caring relatives as to the patient. Maybe if they are happy the patients will also be happy. In view of this, it is questionable whether Cynthia's judgement is of no greater standing than that of others to whom the same information is available. Furthermore, are issues such as Mrs Barker's intentions that her savings should go to Cynthia and the loss of the council tenancy, even theoretically irrelevant when deciding about Mrs Barker's health needs? If Mrs Barker is readmitted to hospital, this would be expensive to society. The cheapest option to society, but the most costly to Mrs Barker, would be for her to go into a residential home. However, should concern for society outweigh concerns for the individual patient?
Perhaps the best way of improving the status quo for Mrs Barker and Cynthia, would be to go along with their wishes and allow them to live together. However, it may be possible to negotiate additional brief periods of respite care to allow Cynthia time for herself, for example to go on holiday. Although this compromised situation may result in continuing relapses, with one admission per year, is this really so bad? Clearly, Cynthia has her own reasons for wanting to sacrifice her freedom to look after her mother, but from the history presented, her decision does appear to be a competent one and consistent with her mother's wishes.

Catherine Oppenheimer, Consultant Psychiatrist, The Warneford Hospital, Headington, Oxford OX3 7JX; Gwen Adshead, Lecturer, Department of Forensic Psychiatry, Institute of Psychiatry, De Crespigny Park, London SE5 8AF; and Jeanette Smith, Senior Registrar, Fromeside Clinic, Blackberry Hill, Bristol BS16 1ED

\title{
Activity in a district psychotherapy service
}

\author{
Richard Tillett
}

\begin{abstract}
The Royal College of Psychiatrists (1991) has recommended that all local mental health services should include speciallst psychotherapy departments. At present these are uncommon outside major teaching centres, although a considerable amount of simple psychotherapy is provided on an ad hoc basis by mental health professionals of various disciplines. This paper describes the structure, functioning and costs of a specialist department in a non-teaching district in the south west of England.
\end{abstract}

\section{Structure}

The Exeter Psychotherapy Service forms part of the mental health services provided by the Exeter and District Community Health Trust for a catchment population of approximately 300,000. About one third of the population lives in or around the city of Exeter, with the remaining two thirds in villages and market towns mainly within $\mathbf{3 0}$ to $\mathbf{4 0}$ minutes drive of Exeter. For the delivery of psychiatric care, the district is divided into six localities (four rural, two within the city), each of which has a multidisciplinary community mental health team operating from a centre within the locality. These teams provide a considerable amount of simple psychotherapy, and some teams include professionals who have had training in a particular psychotherapeutic approach (e.g. cognitive therapy, family therapy etc.).

The Psychotherapy Service is based in Exeter at Wonford House Hospital, which is on the same site as the local district general hospital, and serves as the main administrative and in-patient centre for the district's psychiatric services. The Psychotherapy Department is on the ground floor of the hospital and has its own separate entrance. There are large and small group rooms, a video suite with one-way mirror and telephone link, and five small consulting rooms. There is also a small office but at present no secretary or receptionist; secretarial and administrative support for the service is provided by the consultant's personal secretary. The depart- 
ment is staffed by a consultant psychiatrist with special responsibility for psychotherapy (seven sessions), a part-time clinical assistant (five sessions) and six part-time non-medical therapists who collectively contribute 1.8 wholetime equivalent. Psychiatric trainees are able to attach themselves to the department for training, and on average contribute 0.2 WTE. The department is able to offer expertise in psycho-dynamic psychotherapy, cognitiveanalytic therapy, Gestalt therapy, systemic and psycho-dynamically oriented couple and family therapy, group-analytic and experiential group therapy, and hypnotherapy.

\section{Functions}

\section{Clinical service provision}

The primary function of the department is to provide a specialist psychotherapy service to the district's catchment population, although in practice $10 \%$ of referrals come from outside this area. Referrals come mainly through consultant psychiatrists and general practitioners, with a small number from community mental health teams and voluntary agencies. In 1992, 120 people were referred to the service; the annual rate of referrals is rising by approximately $10 \%$ per annum.

All new referrals are seen for assessment by the consultant or a senior member of the department to explore whether psychotherapy is likely to be an effective treatment for the patient's problems, and if so on what basis. Consideration is given to whether the patient is 'ill enough' to justify specialist NHS psychotherapy, and 'well enough' to be able to make effective use of it. In many cases this assessment can be made in one interview, but some patients are offered a second assessment two weeks later to allow time for reflection and discussion with others. Those living with partners or families are invited to attend a second session with their partner, or other members of the household. In some cases assessment leads to a clear and specific recommendation, while in others a number of different options may be presented for discussion. A number of patients are deflected to other local agencies (e.g. community mental health team, clinical psychology, Relate, private therapists), and some decide themselves not to proceed with therapy after assessment for a variety of psychological and logistical reasons; this is not necessarily a negative outcome (Frayn, 1992).

Audit data from the years 1989 to 1992 show a consistent default rate of $15 \%$ between referral and assessment. In the light of evidence from other centres (O'Loughlin, 1990; Eynon \& Gladwell, 1993) patients are now asked to return a reply-paid slip confirming they wish to attend for assessment. Of those patients who do attend, about $70 \%$ are offered treatment in the department, and $50 \%$ actually enter therapy. Of patients who enter therapy, $35 \%$ complete treatment within six months, $50 \%$ within one year, $85 \%$ within two years and $95 \%$ within three years. Patients are not usually offered more than two years in individual therapy; those requiring further help are offered the chance to join one of the department's out-patient groups.

Patients (and their referrers) often expect to be offered individual psychotherapy; the possible indications for group or family therapy may need to be carefully explained during assessment. In practice we offer individual therapy to about half our patients, the remainder dividing almost equally between group and family therapy. At present the department has a workload of about 80 cases per week, of whom 40 will be seen individually, 20 as couples or families, and 20 in three out-patient psychotherapy groups.

\section{Supervision}

Each of the therapists working in the department is seen regularly for supervision/case discussion by the consultant, who thus maintains some contact with each case. Therapists also participate in fortnightly peer case discussion groups. Supervision is provided by the consultant and other members of the department for other mental health professionals, including junior psychiatrists and non-medical staff. The department runs continuing weekly supervisory groups in group-analytic and cognitive-analytic therapies.

\section{Consultation}

A consultative service is offered to other parts of the mental health service and to other agencies. This may take a number of forms including joint assessment, case discussion, staff selection and support and service planning. Close relationships exist with non-statutory agencies including Relate, The Samaritans, CRUSE and the local hospice and with some departments in the district general hospital.

\section{Teaching}

The department provides regular input to the local postgraduate training course for the MRCPsych, offering both theoretical and experiential training. Two one-year half-day release introductory courses in psychotherapy have taken place, and the department has organised biennial regional psychotherapy conferences since 1986. A one-year half-day release course in group-analytic psychotherapy has taken place for several years, and the department has provided seminars and workshops on a number of different topics. 


\section{Information}

Frequent contacts are made, both by telephone and letter, by professionals and patients seeking information about clinical and training facilities in psychotherapy, both locally and in the rest of the UK. It is usually possible to provide satisfactory information or to direct the enquiry to a suitable person.

\section{Staff support and development}

The department provides leadership for five multidisciplinary staff groups within the mental health service, and for a sensitivity group for psychiatric trainees. All of these have been initiated by staff request and appear to be highly valued. Ten per cent of the department's formal referrals are members of health authority staff and a number of staff refer themselves. The consultant has run weekend and residential groups for mental health staff over a period of 12 years (Tillett, 1986).

\section{Management}

Running the service involves the recruitment, training, support and supervision of staff and the establishment and administration of the departmental budget. Some income is generated through teaching and consultative activities, and some by letting rooms in the department to other agencies on a fee paying basis. Contact with local managers is maintained both directly and through the Division of Psychiatry. A regional group of consultants interested in psychotherapy has been meeting since 1986 on a quarterly basis, and provides a useful forum in a region which is almost $\mathbf{2 5 0}$ miles from end to end. Links with the Royal College of Psychiatrists are maintained through the consultant's function as the College's Regional Representative for Psychotherapy.

\section{Audit}

This has been part of the department's activities from the beginning, initially focusing on crude activity analysis, currently focusing on audit and quality control and moving next to outcome evaluation. These activities have been restricted by the lack of a departmental secretary/ receptionist, and the absence of computerised information handling.

\section{Costs}

The service described is currently provided at an approximate annual staffing cost of $£ 80,000$. This includes the seven session commitment from the consultant and secretary, five clinical assistant sessions, and an annual staffing bud- get of $£ 30,000$. This is used to employ six parttime non-medical therapists most of whom are in private practice locally. They are employed on an honorary basis by the trust which therefore does not pay national insurance contributions for them, and no provision is made for sickness or annual leave or for further training. They are paid on a piece-work basis (at an hourly rate derived from the salary scale for child psychotherapists) for direct clinical work with patients, for supervision and administration (including departmental meetings). In practice over $80 \%$ of therapists' fees are paid for direct clinical work and supervision. Although these arrangements have the advantage of flexibility, some therapists have expressed concern about the uncertainty of the legal and contractual position and the situation allows management to avoid substantiating the service on a more formal basis.

Overhead costs have proved impossible to establish locally, but information from other centres (F. Margison, personal communication) suggests that they are likely to be at least equivalent to the direct staffing budget, suggesting an approximate cost of $£ 150,000-£ 160,000$ for the service described here. Overhead costs may be higher in regional centres with greater training commitments.

\section{Setting up a district service}

The development of a specialist psychotherapy service for a catchment population requires careful planning, and a number of key issues need to be clarified, perhaps by establishing a district psychotherapy planning group. Account must be taken of existing services and staff attitudes towards the development of a new service; those already providing counselling or psychotherapy may feel threatened by the development of a specialist facility. Negotiation with colleagues, managers and purchasing authorities is essential to determine what funding may be available and to discuss service priorities. It may be helpful if those developing the service can offer purchasers some idea of what can be provided for a given sum of money.

The activities of the new service need to be clarified, especially in terms of the balance between direct clinical service, supervision, and training/consultation. It is tempting to combine these by providing the clinical service using trainee therapists, but referrals are likely to be mainly of difficult and intractable cases which trainees may not be competent to deal with effectively. A critical mass of experienced therapists is essential for the provision of a sound clinical service. A district service such as the one described can provide satisfactory general training in psychotherapy (for trainee psychiatrists and 
other mental health professionals), and can provide useful placement experience for specialist psychotherapy trainees from regional centres.

There is growing acceptance of the need for district services to provide a range of psychotherapeutic approaches; a consultant leading such a service will need to have experience in the use of different approaches, and this has implications for senior registrar training (Ryle, 1992). My own view is that a typical district service should aim to provide brief (dynamic, cognitivebehavioural or cognitive-analytic) therapy, as well as longer-term psycho-dynamic therapy; systemic or psycho-dynamic therapy for couples and families, and group therapy. This range of approaches allows service provision to be tailored to the needs of each particular patient. Experience so far in my own department suggests that the potential confusion from different therapeutic 'languages' is not a serious problem, and most therapists welcome the opportunity to learn from each other's approaches.

The relationship of the new service to existing mental health services needs to be considered; some will argue that psychotherapy should be clearly distinguished from the rest of psychiatric services to avoid stigmatisation of clients, while others will be concerned at the potential split in services that can be produced by such clear separation. My own experience over the past ten years suggests that the benefits of integration outweigh the possible dangers of stigmatisation, which has rarely been a significant problem. Similar issues arise with the leadership of the service - both the Royal College of Psychiatrists and the British Psychological Society (1990) have argued the case for members of their own profession to lead psychotherapy services. What is agreed is that whoever leads the service must have appropriate specialist training, and sufficient experience to command respect from other professionals and managers. Whether the service should occupy its own premises or work on a peripatetic basis also requires consideration. In urban areas, working from a central base is probably the most cost-effective approach, but in rural areas where public transport is poor, the service may need to be delivered more locally, for example at GP surgeries or local mental health centres. This must not, however, undermine the service's internal strength and cohesion. Management arrangements must be clarified and satisfactory provision made for audit and quality assurance.

\section{Conclusion}

Setting up a district psychotherapy service has some similarities with the provision of psychotherapy itself. It is a difficult, time-consuming and complex task, and it is tempting to cut corners. But if the planning of such a service is hasty and ill-considered the quality of service provision will suffer. A local psychotherapy service will be required to contain considerable amounts of psychological pain and distress, and the service itself therefore needs to be constructed soundly and properly resourced. Experience in Exeter suggests that it is possible to establish a service at moderate cost which provides a valuable clinical service as well as supporting the work of other professionals. Perhaps the most telling argument is that it is possible for a small district service (without the additional responsibilities of a major regional teaching centre) to provide a year's expert psychotherapy for less than the cost of 14 days' stay in hospital.

\section{References}

BRTISH PSYCHOLOGICAL SOCIETY (1990) Psychological Therapy Services: the need for organisational change. Leicester: British Psychological Society.

EyNON, T. \& GLADWELL, S. (1993) The use of pre-assessment questionnaires in psychotherapy. Psychiatric Bulletin, 17, 149-151.

FRAYN. D. (1992) Assessment factors associated with premature psychotherapy termination. American Journal of Psychotherapy. 46, 250-261.

OZOUGHuN, S. (1990) The effect of a pre-appointment questionnaire on clinical psychologist attendance rates. British Journal of Medical Psychology, 63, 5-9.

ROYAL COLLEGE OF PSYCHIATRISTS (1991) The future of psychotherapy services. Psychiatric Bulletin, 16, 174-179.

RYLE, A. (1992) Sentor registrar in psychotherapy. Psychiatric Bulletin, $16,30-32$

TULETT, R.I.L. (1986) Providing therapy for therapists. Bulletin for the Royal College of Psychiatrists, 10, 27-28.

Richard Tillett, Consultant Psychiatrist/Psychotherapist, Wonford House Hospital, Dryden Road. Exeter, Devon EX2 5AF 